\title{
Villas miseria y favelas: sobre las relaciones entre las instituciones del Estado y la organización social en las democracias de los años sesenta*
}

\author{
Alicia Ziccardi
}

\section{Introducción}

En los años sesenta, algunos países de América Latina marchaban hacia una profundización de los procesos democráticos que, en medio de la inestabilidad política que había prevalecido desde la salida de la Gran Crisis, intentaban finalmente afirmarse. Alternativamente y en diferentes contextos nacionales, regímenes populistas y militares se habían sucedido sin lograr instalar una alianza de clases capaz de sustentar el desarrollo capitalista industrial hacia el que se pretendía marchar autónomamente. En Brasil y Argentina se inauguran, al comienzo de la década, gobiernos elegidos democráticamente a través de un voto restringido por un conjunto de disposiciones institucionales impuestas a las fuerzas políticas populares. A pesar de ello, los partidos políticos que alcanzaron el gobierno intentaron encontrar su principal fuente de legitimidad en la ampliación del espacio político de las clases populares. Los límites de viabilidad de este proyecto fueron impuestos por la alianza de la burguesía nativa con el capital extranjero y las fuerzas políticas reaccionarias que la representaban. Los golpes de Estado que se producen en uno y otro país, entronando respectivos gobiernos militares, constituyen un requisito político indispensable para retomar el rumbo hacia un desarrollo capitalista monopólico en el que la participación política de la clase trabajadora fue excluida mediante la imposición de fuertes mecanismos de control social.

* Quiero agradecer los comentarios realizados a una versión preliminar de este trabajo por los investigadores que participaron en el Seminario "Desarrollo Estructural y Problemas Sociales de la Ciudad Latinoamericana" celebrado en Tepoztlán-México, del 22 al 24 de agosto de 1982. Particularmente a Jorge E. Hardoy por su cuidadosa y crítica lectura y las importantes contribuciones que me brindó. Como es de práctica, las deficiencias que aún pudiera presentar este trabajo son exclusiva responsabilidad de la autora. 
La democracia de aquellos años constituye un período durante el cual las clases populares retornaban o, aun en el caso de algunos de sus segmentos, debutaban en la escena política nacional. Las organizaciones sindicales y los partidos políticos de origen popular constituian sin lugar a dudas los lugares privilegiados para el ejercicio de una ciudadanía que lentamente se iba construyendo. Pero ciertamente no eran los únicos. Para la parcela de trabajadores urbanos que no lograban insertarse plenamente en el mercado de trabajo capitalista, sus primeras experiencias de participación social comenzaban a gestarse en los barrios populares que habitaban. El Estado, los partidos políticos y otras instituciones de la sociedad civil - particularmente de carácter asistencialista y religioso- reforzaron su presencia frente a estos contingentes de trabajadores urbanos y, en cierta medida, disputaban su adhesión a los diferentes proyectos en los cuales pretendían incluirlos. La importancia otorgada a los barrics populares trascendió los propios escenarios nacionales. La estrategia que ideara Estados Unidos para América Latina a fin de impedir el avance de las fuerzas populares y que se corporizó en la Alianza para el Progreso incluía, como todos sabemos, programas destinados a incidir sobre la situación prevaleciente en estos barrios. En Brasil y Argentina el problema de las villas miserias y las favelas cariocas, aun presentando una magnitud diferencial y características particulares, se transformó en el objetivo central de programas de erradicación. Para ello circularon por nuestros países técnicos encargados de realizar evaluaciones que ofreciesen fundamentos a los préstamos que otorgarían las agencias multilaterales ${ }^{1}$ y que orientarían las acciones que las instituciones estatales o municipales emprenderían. Para villeros y favelados, estos programas preveían su desalojo de las tierras en las que se hallaban originalmente y su traslado a viviendas provisionales o definitivas ubicadas en la periferia de la ciudad. ${ }^{2}$ Para ello, un requisito fundamental era impulsar organizaciones de pobladores capaces de subordinarse a los programas gubernamentales $o$, ante la imposibilidad de lograrlo, recurrir al más estricto control social.

La forma ccmo se pretendió imponer esta política en las villas miseria de Buenos Aires y en las favelas de Río de Janeiro, las modalidades que asumieron las instituciones estatales encargadas de su implementación, las respuestas que daban a la cuestión de los barrios populares diferentes instancias de gobierno, la presencia de fuerzas políticas populares que podían representar los intereses de los pobladores ante distintas instancias de poder, la forma como estos trabajadores intentaron impulsar organizaciones

1 Sobre los proyectos financiados y el monto de los préstamos véase Hardoy, Jorge y otros; Financiamiento para los asentamientos humanos en América Latina. Las acti. vidades de las agencias multilaterales, CEUR, Buenos Aires, 1979.

2 Aunque estos programas comenzaron a elaborarse en los primeros años de la década, los mismos sólo se ejecutaron a mediados de la misma, cuando en ambos paises se impusieron regímenes militares. 
sociales que ante la puesta en marcha de estos programas pudiesen estructurar una acción alternativa, serán las cuestiones que intentaré analizar en el presente trabajo.

\section{Las villas miseria de la Capital Federal (1963-1966)}

La decisión de convocar a elecciones en 1963 constituyó un nuevo intento de superación de la inestabilidad política argentina. Los enfrentamientos militares que se sucedieron durante el gobierno provisional del dactor Guido habían puesto en crisis la propia unidad de las fuerzas armadas. ${ }^{2}$ Como respuesta a esas crisis, uno de los sectores, el legalista, pugnaba por sustraer a las mismas del centro de la escena política. Su triunfo permitió la aplicación de su estrategia. El camino elegido fue el de retornar al régimen constitucional.

La voluntad popular como sustento ideológico del gobierno volvió a ser la base del sistema de legitimidad vigente y los partidos políticos el vínculo fundamental entre representantes y representados. Sin embargo, el proyecto estaba viciado desde sus inicios por el incumplimiento de una de sus principales reglas. La proscripción del peronismo dejó fuera del sistema político a la más importante parcela del electorado. ${ }^{4}$ Ese fue el límite dentro del cual las fuerzas armadas accedieron a la restauración del sistema representativo, pero ese sería también uno de los límites más importantes del nuevo régimen.

Desde la caída del régimen populista, la política argentina estuvo signada por la presencia insoslayable de ese movimiento social. Frente a él se ensayaron alternativamente estrategias de disolución o integración sin éxito apreciable. El período inmediatamente anterior al gobierno radical y el gobierno radical mismo estuvieron signados por esa contradicción y esas dcs estrategias. Las fuerzas políticas participantes en la elección se estructuraron alrededor de la contradicción peronismo-antiperonismo.

El triunfo de la Unión Cívica Radical del Pueblo (UCRP) significó el triunfo de las fuerzas antiperonistas. Pero lo ajustado del mismo crearía

3 Durante el gobierno provisional del doctor Guido, se producen enfrentamientos militares entre dos corrientes internas del ejército: los azules, definidos como lega. listas, que sostenían el carácter profesionalista del ejército, reservando la escena politica a los partidos, y los colorados, a los que se denominaba golpistas, que sostenían la necesidad de profundizar la participación de las fuerzas armadas en el gobierno. Véase Guillermo A. O'Donnell, Modernización y autoritarismo, Paidós, Buenos Aires, 1972.

${ }^{4}$ En febrero de 1963 el poder ejecutivo da fuerza de ley al Decreto $7165 / 62$, mediante el cual se establecía la plena vigencia del Decreto 4161/56 por el que se prohibían las actividades peronistas en el país, con lo cual se reiteraba la inhabilitación del régimen derrocado en 1955. 
a los nuevos gobernantes una relación de fuerzas desfavorable para la aplicación, sin trabas, de su proyectc político.

En el parlamento, efectivamente, la fuerza de la oposición llevó a los radicales a tener que aceptar una serie de alianzas y concesiones. $\mathrm{Y}$ esa debilidad relativa respecto al conjunto de las fuerzas políticas que habían participado en las elecciones se vio agravada por la oposición frontal del peronismo. Éste, cuya fuerza orgánica se asentaba principalmente en el control del movimiento sindical, decidió continuar con la aplicación del Plan de Lucha cuya ejecución había comenzado durante el gobierno anterior. El gobierno, para consolidarse, debía ampliar sus bases sociales de apoyo.

El plan de estabilización aplicado entre los años 1962 y 1963 había tenido un fuerte efecto recesivo. El nuevo gobierno basó su proyecto de reactivación fundamentalmente en la expansión del consumo privado. Para facilitarlo impulsó un incremento significativo del salario real. A ellc sumó una política fiscal y una política monetaria y crediticia resueltamente expansivas.

Estas medidas no fueron suficientes. En 1965 hubo elecciones para la renovación parcial del Parlamento nacional y de las autoridades de algunas provincias. El triunfo del peronismo aumentó sus problemas. No sólo porque su control del gobierno se hacía más difícil sino porque los sectores antiperonistas comenzaron a temer que, de mantenerse el gobierno y el régimen electoral, el peronismo triunfara en las elecciones de renovación presidencial.

$\mathrm{El}$ aislamiento del gobierno y las frecuentes luchas sociales fueron, desde los últimos meses de 1965, los elementos característicos de un ambiente en el que los proyectos de golpe de Estado fueron afianzándose. El cambio de gobierno se produjo sin oposición en junio de 1966.

Dentro de la política general del gobierno radical, el intento de ampliar sus bases de sustentación social considerando las demandas populares en sus proyectos constituyó una constante de su actuar político. Cuando los pobladores de las villas miseria expusieron a través de su principal organización - la Federación de Villas y Barrios de Emergencia de la Capital Federal - un conjunto de reivindicaciones, el gobierno nacional demostró interés en entablar un diálogo abierto con los mismos, en otorgar a la cuestión villera un estatus legal para ser incorporada a su agenda gubernamental y en orientar la acción de diferentes agencias estatales hacia la satisfacción de algunos de sus reclamos. La forma como se ocupó de las villas el gobierno nacional responde sin lugar a dudas a la importancia que podía adquirir el comportamiento de este sector popular urbano, en un momento en que las organizaciones sindicales desataban un plan de lucha en oposición a la política gubernamental.

En este sentido, es necesario subrayar que la cuestión de la existencia de las villas miseria en la Capital no constituía un problema de una envergadura comparable a la que el mismo adquiría en otros países latinoamericanos. Las villas se habían ido conformando a través de un proceso de 
ocupación familiar e individual de tierras que, en su mayoría, eran de propiedad pública. En los años sesenta, las instituciones estatales informaban que se trataba de 33 barrios populares que albergaban a menos de 50 mil personas. ${ }^{5}$ Sin embargo, su importancia social no debe ser medida por el peso cuantitativo que poseía su población sino por el hecho de tratarse de una concentración territorial urbana de trabajadores de muy bajos e inestables ingresos, que ocupaban tierras de propiedad de distintos niveles y agencias de gobierno y que habían comenzado a desarrollar formas de crganización representativas de este conjunto social.

La magnitud del problema, así como las necesidades del gobierno de ampliar su legitimidad social, permitían pensar en la posibilidad de la puesta en marcha de una política capaz de ofrecer a los pobladores de las villas alternativas habitacionales. Los gobiernos que sucedieron al régimen peronista habían encarado el problema de las villas miseria tanto desde una perspectiva erradicadora como desde la construcción de viviendas cuya precariedad en nada mejoraba las condiciones de vida que prevalecían en las villas. ${ }^{6}$

Aunque estas políticas no habían llegado a concretarse o sólo se habían transformado en acciones muy limitadas, los villeros ya estaban alertados acerca de las posibilidades de ser desalojados. Al iniciarse el gobierno radical poseían una posición relativamente elaborada sobre sus demandas y una organización capaz de expresarla a los organismos y autoridades encargadas de la cuestión.

Ante esta situación, el gobierno encargó a los representantes del partido radical en el Parlamento la elaboración de una ley de erradicación de villas miseria. A través de la misma se expresaba el compromiso estatal de asumir la responsabilidad de la situación y cierta disposición a otorgar

5 En 1956, la Comisión Nacional de la Vivienda informaba que existían 21 villas miseria con 33920 personas. El censo de la Municipalidad de Buenos Aires de 1963 estimaba la existencia de 33 localizaciones con 42462 habitantes.

${ }^{6}$ En 1956 se creó la Comisión Nacional de Vivienda, organismo cuyo objetivo principal fue la elaboración de un Plan de Emergencia y un Plan Integral a fin de resolver el problema de la crisis de vivienda que afectaba particularmente a los sectores de menores recursos. El primero de los planes mencionados constituía un acabado proyecto mediante el cual se pretendía erradicar el conjunto de las villas de emergencia a través de una decidida acción gubernamental de construcción de viviendas de interés social. Los principales destinatarios serían los pobladores de las villas, los cuales, mediante una subvención estatal, podrían adquirir nuevas unidades habitacionales. El gobierno constitucional de Arturo Frondizi, que sucede al de la Revolución Libertadora, implantó también un proyecto de erradicación esta vez menos ambicioso que el anterior. Por el mismo, se ofrecía a los pobladores de las villas de emergencia una vivienda precaria comúnmente denominada "medios caños", que venía a significar pocas mejoras en las condiciones de habitabilidad respecto de las originales. Véase Martha Schteingart y Beatriz Broide, "Procesos sociales, políticas de vivienda y desarrollo metropolitano", en Manuel Castells (comp.), Estructura de clases y politica urbana en América Latina, Ed. SIAP, Buenos Aires, 1974, pp. 235-286 y Oscar Yujnovsky, Claves políticas del problema habitacional argentino 1955-1981, CEUR, Buenos Aires, 1982. 
un conjunto de facilidades y prebendas para que estos pobladores accedieran a nuevas viviendas. En lo fundamental, el proyecto - que se convirtió posteriormente en la ley 16601 de 1964-, sostenía que: a] el Ministerio de Obras Públicas asumiría la construcción de viviendas, b] se otorgaría a los villeros préstamos gubernamentales con plazos entre 15 y 30 años y c] la cuota de amortización mensual e interés no podía ser menor del $15 \%$ ni mayor del $20 \%$ del sueldo o ingreso del titular de la familia, reajustable con las variaciones del salario mínimo, vital y móvil. Para concretar tal política, el gobierno reiteraba lo que había expresado en otros ámbitos de su actuación: su renuencia a aceptar recursos financieros externos sosteniendo que: "Las bases de la financiación de planes para la desaparición de las villas debían hacerse dentro de la república y en la medida que fuese necesario volcar la ayuda que se había obtenido del BID". "

Sin embargo, la creación de dicha reglamentación normativa no fue suficiente para la puesta en marcha de esta política puesto que, como se verá, la acción gubernamental en materia de nuevas viviendas quedó a cargo del gobierno municipal, el cual, gozando de cierta autonomía, inscribió la misma en fundamentos legales y acciones muy diferentes.

En el nivel de gobierno nacional se consiguieron, no obstante, efectivizar algunas mejoras que habían sido sistemáticamente reivindicadas por los villeros: creación de escuelas, campañas de salud y vacunación, mejoramiento de los principales servicios colectivos (agua, luz). Pero el Ejecutivo Nacional tuvo la capacidad de responder a uno de los principales reclamos de la Federación de Villas: la regularización de la situación legal de los extranjeros que habitaban las mismas. Debe pensarse que un argumento permanentemente esgrimido por las fuerzas reaccionarias era que estos barrios populares constituían un problema generado por la migración de trabajadores de países limítrofes, principalmente bolivianos, paraguaycs y chilenos. El mismo partido gobernante en su fundamento de ley expresaba: "Habría que buscar las causas por las que se ha producido este desarrollo de los barrios de emergencia $[\ldots]^{8}$ aquí tenemos habitantes de todas las nacionalidades [...] casi todos los habitantes de estos barrios son extranjeros. No los despreciamos y les brindamos todas las oportunidades de incorporarse a la familia argentina. El Poder Ejecutivo y este Parlamento, sin distinción de sectores, está dispuesto a apoyarlos". 8

Lo cierto es que aun cuando en las villas habitada por aquel entonces un alto porcentaje de extranjeros, que habían llegado al país tras la búsqueda de empleos y que se incorporaban al mercado de trabajo sin poder cumplir con los requisitos legales existentes, el crecimiento que la población villera experimentará en la década se deberá principalmente a la migración proveniente de nativos del interior del país expulsados por las crisis

7 Fundamentación del proyecto de la Ley núm. 16601.

8 Diario de Sesiones de la Cámara de Diputados de la Nación, 1964, tomo IV, p. 2 488. Véase también Diario de Sesiones de la Cámara de Diputados de la Nación, Sesiones extraordinarias del 12 de agosto al 12 de diciembre de 1963, tomo I, p. 596. 
de las economías agropecuarias. ${ }^{9}$ De todas formas el ejecutivo sancionó en enero de 1964 un decreto de amnistía que beneficiaba a todos aquellos trabajadores de países limítrofes amenazados permanentemente de expulsión y sometidos a una situación discriminatoria en el mercado de trabajo, el cual fue recibido por la Federación de Villas con el máximo entusiasmo. ${ }^{10}$

El conjunto de estas medidas que efectivizó el Ejecutivo y que podrían ser calificadas como una política de corte asistencialista, no se correspondió con la emprendida por las autoridades municipales. En este sentido debe pensarse que, en la época, dada la vigencia de los principios constitucionales, el gobierno de la Municipalidad de Buenos Aires estaba constituido por el intendente municipal y sus secretarios y un órgano deliberativo: el Concejo Deliberante. La elección del intendente era facultad del presidente de la república mientras que el Concejo se hallaba constituido por representantes electos. En este último foro, la presencia de pequeños partidos políticos populares - fundamentalmente el Partido Socialista Argentino y el Demócrata Cristiano- posibilitó que las organizaciones villeras pudieran vehiculizar ante el mismo sus principales reivindicaciones. Esto dio origen a la proliferación de un conjunto de reglamentaciones referidas también al mejoramiento en la provisión de bienes y servicios colectivos y al suministro de materiales para reconstrucción de viviendas afectadas por incendios. ${ }^{11}$

Pero también este Concejo sancionó una ordenanza que se alejaba de las consideraciones incluidas en la Ley Nacional de Erradicación e ideaba y reglamentaba nuevas formas de actuación para los organismos municipales. En la misma se sostenía que: 1] la Municipalidad ofrecería "en venta o alquiler" un porcentaje de viviendas disponibles; b] los pobladores de las villas podían obtener una habitación por autoconstrucción, mediante sistemas de esfuerzo propio o ayuda mutua para lo cual el organismn destinaría terrenos; c] los inmuebles ro podían ser vendidos ni transferidos y gozarían de una exención de impuestos por contribución territorial durante diez años; d] la Municipalidad realizaría obras de desarrollo urbano en las zonas en las cuales se asentaría la población, se encargaría de adoptar medidas de control que impidiesen la expansión o creación de nuevas villas e impulsaría el denominado "desarrollo de la comunidad" a fin de garantizar el objetivo de este plan. ${ }^{12}$

La institución comunal encargada de efectivizar estas acciones era la

${ }^{9}$ Posiciones opuestas y proyectos alternativos fueron expuestos en el Parlamento por el Partido Demócrata Cristiano y el Partido Socialista Argentino. Véase Diario de Sesiones de la Cámara de Diputados de la Nación 1964, tomo IV. pp. 346, 2825,2826 y 2856, y en 1965 pp. $2487,2746,2824$ y 2943.

10 Decreto núm. 49 del 3 de enero de 1964, que modificaba el régimen de admisión. permanencia y expulsión de extranjeros en al país.

11 Véase Alicia Ziccardi, Politicas de vitienda y movimientos urbanos. El caso de Buenos Aires (1963-1973), ceur-Di Tella, Buenos Aires, 1977, anexo 2, pp. 248 a 252.

12 Ordenanza Municipal núm. 20220 de ahril de 1965. 
Comisión Municipal de la Vivienda, creada en 1961 con el objetivo primordial de proveer vivienda a familias de bajos ingresos. ${ }^{13}$ Este organismo, cuya acción era más amplia que ocuparse de la cuestión villera, elaboró y puso en marcha el denominado Plan Piloto de Erradicación de las Villas núms. 5, 6 y 18 del Parque Almirante Brown. ${ }^{14}$

Al iniciarse la década de los años sesenta la Municipalidad de Buenos Aires había previsto un gran programa de desarrollo urbano en una zona de bañados en la que se hallaban situadas varias villas, denominada Parque Almirante Brown. La realización de dicha obra demandaba una importante inversión de recursos y en el marco de la Alianza para el Progreso la comuna gestionó un crédito del Banco Interamericano de Desarrollo (BID). El organismo internacional envió expertos para que realizaran una evaluación social de la población villera y señalaran lineamientos específicos para proceder al traslado de los habitantes. ${ }^{15}$ Como resultado de esta acción el gobierno comunal intentó impulsar organizaciones vecinales subordinadas al mismo; la construcción de locales para el funcionamiento de centros de la comunidad, clubes de madres, juntas de vecinos; la formación de grupos voluntarios para la realización de obras de mejoras; campañas sanitarias, etcétera. ${ }^{16}$ Pero durante el período no fue trasladada ninguna villa y será con posterioridad a la imposición del régimen militar cuando las villas declaradas prioritarias se verán afectadas por estos planes de erradicación. En cierta medida debe pensarse que un obstáculc que enfrentó la política municipal fue que la clave del programa social - la organización de la comunidad - no era fácil de ser puesta en marcha en una realidad en la cual los pobladores eran ya conocedores del significado de las mismas. Para ese entonces las villas contaban con organizaciones propias de tipo recreativo (clubes de fútbol) y reivindicativo (juntas o comisiones vecinales o clubes de madres). ${ }^{17}$ Desde 1958 estas agrupaciones habían dado origen a la Federación de Villas y Barrios de Emergencia de la Capital Federal. La eficacia de estas organizaciones ya había sido puesta a prueba ante los intentos de desalojo, cuya

13 La Comisión Municipal de la Vivienda fue creada orgánicamente en 1961 y venía a continuar los trabajos realizados por la Dirección Municipal de la Vivienda, orgamismo constituido en 1946. Véase Alicia Ziccardi, op. cit., pp. 71-72.

14 Idem, pp. 73-80.

15 En 1964, el BID encomendó a la Foundation Cooperative Housing que realizara un informe para evaluar la viabilidad del proyecto y dictaminara sobre la posibilidad de conceder el préstamo solicitado por la Municipalidad de Buenos Aires. Albert Wilson fue el encargado de realizar este estudio titulado: Análisis socioeconómico de los residentes de las villas de emergencia en el Parque Alte. Brown, Comisión Municipal de la Vivienda, Buenos Aires, 1965.

16 Véase Plan piloto para erradicación de villas de emergencia núms. 5,6 y 18, Comisión Municipal de la Vivienda, Buenos Aires, 1966. También: Acción en las villas de emergencia. Planificación para el desarrollo de esas comunidades 1963-1966, Comisión Municipal de la Vivienda, Buenos Aires, 1966.

17 Sobre el comportamiento de estas organizaciones naturales durante el periodo, véase Alicia Ziccardi, op. cit., pp. 80-91. 
concreción habían logrado evitar. Para ello, las organizaciones villeras habían sabido gestar apoyos externos: los partidos políticos y el movimiento sindical organizado.

Un elemento fundamental en torno a la organización villera que por aquel entonces comenzaba a consolidarse, era la autonomía que los dirigentes imprimían a sus agrupaciones, tanto en relación a las instituciones del Estado como de la sociedad civil. Esto no quiere decir que la Federación no siguiese lineamientos políticos globales puesto que de hecho adhería a la estrategia del Partido Comunista. Lo fundamental es que su accionar estuvo signado por el intento de extender y profundizar la organización villera y para ello la base de su actuación fueron sus propias reivindicaciones más que su identificación con una estrategia política global.

Hasta 1963 la Federación de Villas y Barrios de Emergencia de la Capital Federal desarrolló casi exclusivamente una acción tendiente a lograr su constitución definitiva. La movilización efectuada al asumir Arturo Illia como presidente de la nación, apoyando su posición de gobierno y alentándolo a cumplir su programa, indicaba que la Federación estaba dispuesta a reclamar un espacio en la escena política. ${ }^{18} \mathrm{Su}$ acercamiento inicial al nuevo gobierno debe interpretarse en el marco de la política global del Partido Comunista. ${ }^{19}$

El primer memorial entregado al ya electo presidente de la nación, decía: "Éste seguramente es el sector social del que menos votos ha obtenido el radicalismo. Sin embargo, estamos aquí para manifestarles solemnemente que nos tendrán junto a ustedes en cualquier situación que les toque vivir por dar cumplimiento al plan prometido y por luchar por resolver los graves problemas que soporta nuestro pueblo." 20

Durante todo el período radical la Federación de Villas mantuvo una relación directa y fluida con el poder ejecutivo. Frente al carácter en cierto modo paternalista de las medidas de este ámbito gubernamental, la Federación presentó un proyecto autónomo, impulsando al mismo tiempo la satisfacción de sus necesidades inmediatas. Esta posición no provocó demasiados conflictos en la relación con el poder central sino que por el contrario permitió que esta organización sectorial mantuviera legitimidad

18 "En la Asamblea de la Federación de Villas y Barrios de Emergencia del 12-9-63 se resolvió que 20000 habitantes de las villas, encabezados por dirigentes de la Fe. deración, organizaran una marcha por las calles de Buenos Aires, frente al Congreso y la Casa de Gobierno, el día 12 de octubre, para manifestar su apoyo al nuevo gobierno con el fin de que pueda dar solución al grave problema de la vivienda." Diario La Razón, 13 de septiembre de 1963.

19 Este partido convocó a sus frentes a una movilización el día que asumió el go. bierno radical. Véase Rubén Iscaro, Historia del movimiento sindical, Ed. Fundamentos, Buenos Aires, tomo II, 1973.

20 Memorial entregado al presidente electo en la entrevista del 12 de agosto de 1963, publicado en el diario La Razón el 13 de septiembre de 1963. 
institucional. Esto fue, al mismo tiempo, lo que permitió que se fueran satisfaciendo sus reclamos a través de los más altos niveles gubernamentales.

Así, descle un principio los pobladares de las villas de emergencia solicitaron a los gobernantes electos:

que nadie sea desalojado de las villas sin antes ofrecerles una vivienda decorosa; que se respete la inviolabilidad del domicilio; que la Municipalidad, Vialidad y el Gobierno faciliten elementos para mejoras, para lo cual todos los vecinos pondremos mano de obra completamente gratuita; que se derogue en forma inmediata el Decreto $4805 / 63$ y se suspenda la expulsión de nuestros hermanos paraguayos, chilenos y bolivianos, declarando una amnistía general para todos los que habitan y trabajan en nuestro país o que les sea entregada documentación nacional; que para adjudicar las viviendas que la Muncipalidad posee en Almirante Brown, en Bonorino, Zaraza y parte de los Perales, se constituya una comisión integrada por la Municipalidad de Buenos Aires, la cGT y la Federación de Villas a fin de evitar favoritismos personales o dar prioridad a las familias más necesitadas; que el gobierno nacional facilite a la Federación de Villas un inmueble donde pueda funcionar normalmente a fin de prestar una mayor ayuda en la organización y ejecución de los trabajos en todas las villas. ${ }^{21}$

Ya se ha visto que el gobierno nacional decidió encarar la resolución de estos problemas. El compromiso oficial se expresó públicamente al participar un representante gubernamental en una asamblea de 400 delegados que la Federación de Villas de Emergencia realizó en la Confederación General del Trabajo en septiembre de 1963, donde se aseguró que no habría desalojos y que el nuevo gobierno encararía con la mejor buena voluntad la solución integral del problema de las villas de emergencia. ${ }^{22}$

Hacia el final del período esta relación se vio alterada. El partido gc bernante, habiendo perdido el control de los resortes gubernamentales, no pudo impedir que se reanudaran algunos de los problemas en parte resueltos. A finales de 1965 la Federación envió una carta al presidente de la nación en la cual comunicaba la situación en que se hallaban, centrando sus reclamos alrededor de la reanudación de las amenazas de desalojos; de los incendios (a los que calificaban de "no tan casuales" ya que eran en cadena); de las prácticas discriminatorias y las inspecciones periódicas; de la suspensión de obras de mejoramiento desoyéndose los compromisos asumidos y de la situación generada por la no reconstrucción estatal de las villas quemadas a pesar de que el Concejo Deliberante había asignado partidas para estas obras. ${ }^{23}$

En síntesis, los pobladores señalaban particularmente su desaprobación

21 Idem.

22 Idem.

23 Véase Alicia Ziccardi, op. cit., pp. 91-97. 
a la política desplegada por el gobierno comunal. En este sentido la relación con el gobierno comunal a nivel de la Intendencia y de la Comisión Municipal había sido de abierta oposición. La intención municipal de erradicar los nucleamientos villeros del Parque Almirante Brown y su reubicación en otro predio no contó con el aval de la Federación de Villas. El incumplimiento de lo reglamentado por el Concejo Deliberante y el pretendido desconocimiento por parte del gobierno municipal de las organizaciones reivindicativas y de la organización sectorial, crearon fuertes enfrentamientcs. El carácter asistencialista de su política y sobre todo el intento explícito de crear organizaciones atomizadas y controladas por la Municipalidad, a través de la "promoción social", produjo fuertes resistencias entre los pobladores.

Ahora bien, estas organizaciones del sector villero desde el punto de vista de sus fuerzas propias, tenían cierto poder o, quizá mejor, cierta capacidad de presión. Pero la misma estaba dada más que por su importancia numérica por la concentración territorial urbana de sus adherentes y en algunos casos por la centralidad geográfica de la villa en el ámbito de la ciudad.

Al mismo tiempc, durante este período la Federación de Villas incrementó ese poder desplegando una clara política de alianzas con el movimiento obrero organizado en la CGT. Un indicio de esta búsqueda de apoyos externos puede encontrarse en el pedido de constitución de una comisión con la representación de la CGT y del gobierno comunal para la adjudicación de viviendas a cargo de la Municipalidad de Buenos Aires. El efecto de esa política de acercamiento puede también encontrarse en la cesión, por parte de la CGT, de su local para las reuniones y asambleas de la Federación de Villas.

A pesar de que la Federación se identificaba con la estrategia del Partido Comunista, una de sus principales características fue la de mantener cierta autonomía de acción inmediata en relación a dicha estrategia política. Es decir, la Federación de Villas adhería a la táctica política global sintéticamente expresada al iniciarse el gobierno radical, en: "apoyar todas las medidas positivas del gobierno, criticar constructivamente sus pasos negativos y enfrentar las presiones mediante la movilización de masas, a fin de que el gobierno cumpliera las promesas hechas a la nación". ${ }^{24}$

Frente a esta posición las corrientes del peronismo - las 62 Organizaciones- asumieron una oposición sistemática pretendiendo desde el inicio continuar con el Plan de Lucha, ya elaborado antes de asumir el nuevo gobierno.

A pesar de ello esa autonomía de la Federación en su accionar permitió que en un principio la organización villera pudiera hallar una importante apoyatura en la conducción cegetista. Más aún, hacia 1965 la ruptura de la unidad de las corrientes peronistas en el seno del movimiento sindical permitió que la relación entre la GGT y la Federación de

24 Rubén Iscaro, op. cit., tomo II, p. 37 . 
Villas se hiciera más estrecha. ${ }^{25}$ Indicios de esa profundización pueden hallarse en distintas actividades solidarias que la CGT tomó hacia los pobladores de las villas de emergencia. Frente a los intentos de desalojos, por ejemplo, la CGT adhirió a la lucha villera; frente a la reanudación de los controles de los organismos estatales, lanzó comunicados y pidió explicaciones al Ministerio del Interior. ${ }^{26}$

Ahora bien, el campo de sus alianzas también lo compusieron pequeños partidos políticos populares. La Democracia Cristiana y el Partido Socialista Argentino, fueron las principales fuerzas políticas que, como ya se dijo, desde el Parlamento y desde el Concejo Deliberante vehiculizaron las reivindicaciones villeras. Sin embargo, su acción fue más bien puntual; sólo participaron y apoyaron conflictos aislados, elevando proyectos que en el primero de los órganos deliberativos, no lograron ser transformados en Ley. En el Concejo Deliberante, como ya se dijo, lograron sí una frondosa legislación respecto a medidas de ayuda inmediatas.

Esa política de alianza permitió a la Federación de Villas obtener una serie de conquistas y fundamentalmente obtener legitimidad como organización representativa de un sector de la población urbana. Pero la importancia que alcanzó en la coyuntura política no siempre estuvo acompañada por una activa participación de sus representados aun en los momentos más intensos de la lucha. Esa falta de participación fue objeto de una frecuente preocupación de sus líderes. El efecto de la misma, desde el punto de vista de la organización, fue una notoria separación entre dirigentes y bases. Frente a esa falta de participación los dirigentes tendieron a crear mecanismos autosuficientes en el funcionamiento de las juntas vecinales y la Federación de Villas y Barrios de Emergencia.

En síntesis, en este período el movimiento reivindicatorio de los pobladores de las villas de emergencia comenzó a reclamar cierto espacio en la escena política. Las características de la coyuntura política - la vigencia de los principios constitucionales y la posición del partido gobernante de ser fiel a los principios de la democracia representativa- permitió que la Federación de Villas obtuviera reconocimiento institucional. Ello sin duda redundó en favor de la obtención de sus reclamos. Pero si bien esa fue la característica principal de su relación con el gobierno nacional, frente al gobierno comunal, en cambio, mantuvo una relación de franco enfrentamiento. Sus alianzas con el movimiento obrero y con los partidos polí-

25 Las dos principales tendencias peronistas en el movimiento sindical fueron las lidereadas por Augusto Timoteo Vandor y José Alonso. El primero, a fin de fortalecer su posición, decidió propiciar una apertura para sumar en su favor el sector de los independientes y el Movimiento de Unidad y Coordinación Sindical (mucs) ligado al Partido Comunista. Sobre esto véase Rotondaro, Realidad y cambio en el sindicalismo argentino, Ed. Pleamar, Buenos Aires, 1971 y Rubén Iscaro, op. cit.

${ }^{26}$ Comunicado de prensa de la CGT núm. 319 del 24 de enero de 1966, referido al barrio Lacarra. 
ticos de origen popular permitieron incrementar su potencialidad aglutinadora, pero la falta de participación activa del conjunto de la población constituyó la limitación principal para su desarrollo organizativo.

\section{Las favelas de Río de Janeiro (1961-1964)}

El golpe militar de 1964 marca el fin de la vigencia de los principios democráticos y el inicio de una sucesión de gobiernos militares que se prolongará hasta nuestros días. La sociedad brasileña entraba así en un proceso de restructuración que respondía al objetivo de lograr la expansión del patrón de acumulación, inaugurado bajo el gobierno de Kubitschek, y que encontraba en la alianza de clases sobre la que se sustentaba el populismo, fuertes limitaciones para su concreción.

Ya en la etapa final del gobierno de Kubitschek comenzaba a tornarse evidente que esa sostenida expansión de la producción de bienes de consumo durable estaba gestando una crisis generada por la enorme gravitación de las empresas de capital extranjero. ${ }^{27}$

La aceleración del proceso de concentración del capital y del ingreso constituían las manifestaciones más visibles del nuevo rumbo que estaba tomando la economía. Los mecanismos inflacionarios, en tanto recursos de que se valió la política económica para demorar el desencadenamiento de la crisis, trajeron aparejada una caída sostenida del salario real de los trabajadores frente al constante incremento del costo de la vida. Si la opción de contraer el consumo de los asalariados urbanos constituía una alternativa posible, también era de esperar, y de hecho fue lo que ocurrió, que dicha política jaqueara la alianza que sustentaba el proyecto "populista-desarrollista" afectando una de sus principales fuerzas sociales. Prueba de ello fueron las movilizaciones populares que, particularmente, impulsadas por las organizaciones sindicales, hacían de la defensa del salario real de los trabajadores su principal eje reivindicatorio.

Durante 1961 y bajo la fugaz gestión de Janio Quadros se intentó poner en marcha algunos mecanismos de saneamiento de la economía a fin de frenar el ritmo creciente de la espiral precios-salarios. Sin embargo, no contando con el aval del conjunto de las fuerzas políticas que participaban del pacto de denominación, su concreción no fue lograda. Tal es el caso de las propuestas de implementar una reforma cambiaria y una reforma fiscal que la composición de fuerzas en el Parlamento no permitió sancionar. Frente a ello, y debiendo hacer frente a una crítica situación presupuestaria, las emisiones monetarias constituyeron nuevamente el pa-

27 Cfr. Francisco De Oliveira, $A$ economía da dependencia imperfeita, Graal, Río de Janeiro, 1978, p. 92. 
liativo al que debió recurrirse para hacer frente a la difícil situación económica. ${ }^{28}$

Con la renuncia de Quadros y en medio de un clima de fuerte inestabilidad política asumía el gobierno João Goulart. La alianza política en la que se apoyó para llevar adelante las llamadas "reformas de base", en vistas al logro del desarrollo de un capitalismo nacional y autónomo, no consiguió neutralizar la acción de las fuerzas opositoras -representadas partidariamente en el PSD y en la UDN en el Parlamento. El tumultuoso escenario político se caracterizaba, entre otras cosas, por las crisis parlamentarias que se desarrollaron a partir del plebiscito de mayo de 1962, la fragilidad que comenzaba a presentar la alianza PTB-PSD, apoyo político fundamental sobre el que se dio inicio a la gestión gubernamental, los conflictos sociales que se manifestaban especialmente en las movilizaciones campesinas en torno a la "cuestión agraria" y también en los movimientos urbanos que protagonizaban los sectores populares. No obstante, ello no impidió que se llevaran a cabo, en octubre de 1962, las elecciones parlamentarias y de los Estados cuyos resultados vinieron a fortalecer el proyecto populista, y que, en los primeros días de 1963, se lograse establecer finalmente el régimen presidencialista y se pusiese en marcha el programa de reformas de base.

Si hasta ese momento la política económica se proponía, mediante una recesión controlada, frenar la tendencia a la profundización de la presión inflacionaria existente, la elaboración y sanción del Plan Trienal de Desarrollo Económico (1963-1965) no sólo reafirmaba este objetivo sino que agregaba también la finalidad de mantener el crecimiento de la economía que se había logrado en los últimos años. Por otra parte, en dicho plan se anunciaba el propósito de llevar adelante una política redistributiva en vistas a reducir el costo social sobre el que se había sustentado el desarrollo: las desigualdades regionales y del nivel de vida de la población.

Sin embargo, como ya varios autores han señalado, el Plan de Furtado encerraba una contradicción entre el objeto económico (que tendía en última instancia a ofrecer las condiciones de restablecimiento del cálculo económico que permitiera dar continuidad al proceso de acumulación del capital) y la alianza política en la que se apoyaba (en la cual era imposible, dado el peso fundamental que tenían los trabajadores, intentar hacer que recayeran sobre éstos los costos que generarían tales decisiones gubernamentales). ${ }^{29}$ La política entonces adquiría una fuerte centralidad y la cuestión de la vivienda popular se transformaba en una preocupación que concitaba el interés tanto de las instituciones de la sociedad civil como del aparato gubernamental.

Los intentos del gobierno nacional de encarar el problema de la vivienda popular formaban parte de un proyecto que no podía omitir en su agenda

28 Véase Paul Singer, "O milagre brasileiro, causa e conseqüêcias", en Cuaderno CEBRAP núm. 6, São Paulo, 1972.

29 Francisco De Oliveira, op. cit. 
la mejoría de las condiciones de vida de la población. Hasta entonces, las acciones emprendidas por los arganismos gubernamentales, fundamentalnente en el caso de las viviendas precarias instaladas en las favelas, habían intentado abordar la cuestión de manera parcial, estigmatizando las características que reunían los sectores populares que habitaban las mismas e intentando paliatiros que en poco habían contribuido a mejorar la situación en que se hallaban. En este sentido debe recordarse que las favelas fueron objeto de atención no sólo gubernamental sino de instituciones de la sociedad civil muy tempranamente. Pero en los proyectos que intentaron poner en marcha diferentes agencias, se evidenciaba más una preocupación por el comportamiento y la potencialidad política que podía tener este grupo, que un verdadero interés en colocar esfuerzos para que pudieran mejorar sus condiciones de vida.

No cbstante la ausencia o puntual intervención estatal que había demandado la cuestión durante gobiernos anteriores, los limitados recursos disponibles y el cúmulo de prioridades sociales, el gobierno federal decidió encarar el problema y efectivizar un conjunto de medidas muy limitadas frente a la magnitud de las necesidades.

En este sentido, la política habitacional atravesó dos momentos significativos. Durante el fugaz gobierno de Janio Quadros se propuso impulsar la autoconstrucción de viviendas, la formación de cooperativas y la participación del Estado en el financiamiento y en la asistencia técnica. También se creó el denominado Consejo Nacional de Planeación de Vivienda Popular, el que no alcanzó a desempeñar un papel significativo y cuya actuación, según se ha evaluado, se limitó a meras propuestas en el ámbito de la burocracia estatal. ${ }^{30}$

Con la renuncia de Janio Quadros asume la presidencia João Goulart en medio de un tumultuoso escenario político y con el condicionamiento, que se le impone, de gobernar bajo un régimen parlamentarista hasta 1963. Su gestión planteó la necesidad de institucionalizar la participación de las organizaciones sindicales en la resolución del problema habitacional. El Ministerio de Trabajo y Asistencia Social puso en marcha un plan habitacional, bajo el eslogan de "tornar cada operario en un propietario', que contó con la reserva de algunos sindicatos que consideraron que, frente a la situación crítica de la vivienda, era imposible que con los escasos fondos asignados por el gobierno dicha situación pudiera revertirse y podía darse lugar a mecanismos arbitrarios en la adjudicación de créditos. ${ }^{31}$

En 1962, Goulart había creado un denominado Consejo de Política Urbana (COPURB) el cual estaba subordinado directamente a la Presidencia de la República y cuya función era coordinar el conjunto de entidades encargadas de la política habitacional. De hecho, con dicho Consejo se pretendía controlar la acción desarrollada por algunos gobernadores,

30 Cfr. Olga Bronstein, Estructura urbana, distribução da população e sector público, tesis de maestría, COPPE, Río de Janeiro, 1979, p. 77.

31 Véase Semanario Novos Rumos, 17 al 23 de agosto de 1962, Río de Janeiro. 
entre ellos Carlos Lacerda en la Guanabara, que negociaban autónomamente los recursos provenientes de la Alianza para el Progreso y los dedicaban a los más diversos fines políticos. ${ }^{32}$

Con posteridad a 1963, cuando se logró restablecer el régimen presidencialista y se puso en marcha un programa de "reformas de base" tendientes a implementar una política de redistribución del ingreso, el gobierno federal, que había otorgado un número importante de financiamientos para la construcción o remodelación de casa propia en diferentes Estados del país, se opuso explícitamente a los métodos represivos mediante los cuales se pretendía erradicar las favelas. Pero el gobierno de la Guanabara se apartó de cualquier lineamiento federal. ${ }^{33}$

Carlos Lacerda, apoyado por la UDN y el PSD, obtuvo la gobernación por un escaso margen de votos otorgados principalmente por las capas medias urbanas, frente al candidato de las fuerzas populares (PTB-PS) Sergio Magalães. ${ }^{34}$

Ya durante la campaña Lacerda había puesto de manifiesto un ambicioso proyecto de: 1] transformar al Estado naciente -antes capital de la república - en una entidad principalmente industrial y 2] realizar profundas modificaciones en la estructura urbana de Río de Janeiro (obras de infraestructura tales como la provisión de agua, sanidad, túneles, etcétera). En relación a esta segunda cuestión, manifestaba el objetivo de mejorar las condiciones de vida de las capas medias y de la burguesía cariocas. Los favelados, en cambio, sólo eran incorporados en el discurso del futuro gobernador como la reserva de mano de obra necesaria para el desarrollo del polo industrial. ${ }^{35}$ Bajo la fundamentación de que las obras de infraestructura los requerían y/o porque eran la fuerza de trabajo disponible para la instalación de las industrias que se esperaba localizar en la periferia de Río, el destino de los favelados era su traslado hacia otras localizaciones, para lo cual se construirían 2250 viviendas de bajo costo. Este programa general fue acompañado de la distribución limitada de algunos bienes indispensables en ciertas favelas y de un proyecto de urbanización de dos favelas ubicadas en la zona norte (Villa Penha y Madureira). Para emprender estas acciones se firmó un acuerdo entre el gobierno de la Gua-

32 Véase Moniz Bandeira, O governo João Goulart. As lutas sociais no Brasil 1961. 1964, Civilização Brasileira SA., Río de Janeiro, 1978, 5a. ed., p. 107.

33 Véase João Goulart, Mensagem ao Congresso Nacional, na abertura da Sessão Legislativa, Brasilia, 1964.

${ }_{34}$ Mientras que a la UDN adherían las capas medias urbanas, el PSD era represen. tativo de los sectores más conservadores del medio rural. Cfr. Glaucio Soares, "As bases ideológicas do lacerdismo", en: Civilização Brasileira, año I, núm. 4, Río de Janeiro, 1965 y "La política de un desarrollo desigual", en Revista de Ciencias Poli. ticas y Sociales, año IX, núm. 23, unam, México, abril-junio, 1963.

35 Cfr. Carlos Lacerda, Discurso Programa da convençâo de udN: Retrato de una cidade desvastada e sua reconstrução, Río de Janeiro, 1960. Es probable que el voto favelado se haya volcado principalmente hacia Tenorio Calvacanti, representante de un pequeño partido, el Prin; véase Carlos Lacerda, Depoimento, Ed. Nova Fronteira, 24 ed., Río de Janeiro, 1978, p. 214. 
nabara y la Agencia Norteamericana para el Desarrollo Internacional (USAID), llamado "Fundo do Trigo", mediante el cual 2857000 dólares obtenidos por Estados Unidos por la venta de productos agrícolas al Brasil serían utilizados para el cumplimiento de los objetivos mencionados. ${ }^{36}$

Las fuerzas populares, aunque en minoría en el Parlamento, pugnaron desde el inicio porque se definiera una política de favelas que contemplara las demandas de este sector popular urbano. Así lograron introducir en la nueva Constitución Estatal de 1961: 1] el reconocimiento oficial de la existencia de las favelas; 2] que se asigne el $3 \%$ de la recaudación tributaria a la creación y mantenimiento de un organismo que implemente una solución; 3] que se mejoren provisionalmente estos asentamientos a menos que fuera demostrado su carácter de "irrecuperable", caso en el cual se podía proceder a la erradicación de los mismos. En los hechos, el escaso control que podían ejercer los representantes de las fuerzas populares sobre el ejecutivo llevó a que los recursos económicos asignados no pudieran ser fiscalizados por aquéllos, a que bajo el fundamento de "irrecuperabilidad" se iniciara un masivo proceso de erradicación y a que la asistencia a las favelas se redujese a montos insignificantes.

El gobierno realizó para ello una reorganización institucional que en síntesis consistió en extinguir aquellas agencias que ya tenían una cierta trayectoria en la propuesta de urbanización de favelas, como era el Servicio de Recuperación de las Favelas (SERFHA), limitó las funciones de otras, como fue el caso de la Cruzada São Sebastião creada por dom Hélder Cámara; fortaleció la Fundación León xir, hasta entonces institución privada que luego incorporó al aparato del Estado, y creó en 1962 un nuevo organismo: la Compañía de Habitación Popular (COHAB). Estas dos últimas instituciones quedaron encargadas del programa de las favelas.

La tarea que tenían por delante la Fundación León xir y la сонав era ardua. Por ese entonces, según datos censales, la población de las favelas alcanzaba a 335063 habitantes, localizados en 147 favelas y con una tasa de crecimiento de $7.04 \%$ entre 1950 y 1960, mientras la ciudad de Río de Janeiro en su conjunto lo hacía al 3.3\% en el mismo período. ${ }^{37}$ A fin de trasladar a los favelados, el gobierno construyó 7720 unidades habitacionales que conformaban tres conjuntos: Villa Kennedy (5069 unidades), Villa Alianza (2 187) y Villa Esperanza (464). ${ }^{38}$ Los mismos estaban compuestos de cinco tipos diferentes de habitaciones que oscilaban entre los 30 y 47 metros cuadrados. Además, se puso en marcha durante este

${ }^{36}$ Cfr. Anthony y Elizabeth Leods, A Sociología do Brasil urbano, Zahar Editores, Río de Janeiro, 1978, pp. 216-217.

37 Cfr. Lucien Parisse, "Las favelas en la expansión urbana de Río de Janeiro: estudio geográfico", en América Latina, vol 12, núm. 3, Río de Janeiro, julio-septiembre de 1969.

38 Las informaciones sobre la población erradicada y la capacidad de los conjuntos habitacionales fueron extraídas de Licia Valladares, Passa-se uma casa, Zahar, Rio de Janeiro, 1978. Con el dinero proveniente del USAID fueron construidos los primeros tres conjuntos habitacionales citados. Cfr. Olga Bronstein, op. cit., p. 178. 
período la construcción de otro conjunto llamado Ciudad de Dios, compuesto de 3865 casas, 1660 departamentos y 1193 unidades "provisionales". Aun cuando los conjuntos presentaban diferentes condiciones de habitabilidad y equipamiento, ya que no todos estaban destinados a la población favelada, al darse comienzo al realojamiento de ésta lo común era que las deficiencias e inconvenientes que debían soportar sus habitantes fuesen gravísimos: distantes de sus lugares de trabajo y sin transporte adecuado para movilizarse, carentes de los servicios más elementales como agua y luz, sin equipamiento (por ejemplo, falta de escuelas para los niños) y debiendo afrontar el pago de una cuota que afectaba notablemente el presupuesto familiar. En esas condiciones, el proceso de erradicación no fue algo que aceptaron los favelados pasivamente. Muy por el contrario, hasta donde sus fuerzas lo permitieron desataron una fuerte oposición.

Los primeros intentos de desalojo comenzaron a fines de 1963 en la favela del Pasmado, ubicada en la zona sur, en terrenos de alto valor comercial. Piénsese que por aquel entonces el régimen de Goulart estaba ya seriamente amenazado por el golpe militar que finalmente se produce en marzo del 64, y en el cual Lacerda sería uno de los principales protagonistas entre los civiles que participaron. Esta favela había sido declarada potencialmente urbanizable durante la existencia del SERFHA. Sin embargo, con el argumento de que era "peligrosa e inurbanizable" se emprendía su erradicación. Años más tarde, Lacerda en sus testimonios declaraba que su objetivo principal era construir en dichos terrenos el Hotel Hilton. ${ }^{33}$ Los pobladores se organizaron pero sólo consiguieron postergar por unos meses el traslado que, finalmente, se efectuó después del derrocamiento de Goulart. Los métodos a los cuales apeló el gobierno fueron claramente expuestos por el ex gobernador:

... Fue una cosa indescriptible. Surgió el rumor de que la gente no se quería mudar. $Y$ algunos no querían realmente, porque eran obreros de la construcción civil en los rascacielos de Copacabana y preferían vivir allá pésimamente, pero cerca del trabajo. Ahora, la mujer y los hijos que se quedaban en casa, en el barro, en la miseria, querían salir. Los hombres querían la comodidad de vivir cerca del trabajo. Una forma de machismo. Entonces Sandra ${ }^{40}$ tomó aquel mujerío, lo metió en el ómnibus del Estado y las llevó para ver las casitas que se estaban haciendo en Villa Alianza. Cuando volvieron a la casa, entonces le pusimos fuego a los barracos. Y ahí, me llamaron Nerón..." 41

Se iniciaba así un proceso de erradicación masiva que duró más de diez

39 Cfr. Carlos Lacerda, Depoimento, op. cit., p. 233.

40 Se refiere a Sandra Calvacanti, secretaria de Servicios Sociales durante su ges. tión y que luego fue la primera presidenta del Banco Nacional de Habitación.

41 Carlos Lacerda, Depoimento, op. cit., p. 233. 
años. La población afectada, si bien consiguió frenar algunas veces la erradicación (aunque sea de manera parcial como ocurrió en la favela Bras de Pina), no pudo evitar que sus posibilidades de manifestar oposición fuesen crecientemente ahogadas a medida que el régimen militar se consolidaba. En cierta medida puede decirse que los favelados carccían de una organización social capaz de gestar un proceso de oposición ante el agresivo plan gubernamental. Su capacidad organizativa respondía principalmente a la presencia de agentes externos, particularmente instituciones estatales y religiosas, y sólo en menor medida a fuerzas políticas populares.

Las favelas supieron desarrollar en su interior un tipo de organización inédita en América Latina: la escola de samba. También proliferaron las asociaciones religiosas como producto del sincretismo que prevalece. Muchas de las comisiones vecinales fueron impulsadas, hacia finales de los años cincuenta, por las mismas instituciones del Estado. ${ }^{42}$ Pero todo esto sólo puede considerarse como formas de agrupaciones voluntarias que si bien contribuyen a definir y reforzar una identidad colectiva, a partir de compartir un conjunto de condiciones de vida deficitarias, no eran suficientes para generar un proceso movilizador frente a un acabado proyecto estatal de refuncionalización del espacio urbano.

Varios trabajos han recalcado que por aquel entonces el tipo de vínculos que entablan los favelados con representantes de partidos políticos eran de carácter personalista y clientelista. Se supone que el peso cuantitativo de los favelados en el interior del conjunto de la población caricca los transformaba en una masa importante de votantes. La contrapartida de este supuesto apoyo electoral era el obtener algunas mejoras en los barrios que habitaban. ${ }^{43}$ Sin embargo, hacia los años sesenta, nuevas formas de organización y lucha de las clases populares se iban desarrollando y los proyectos globales de las fuerzas políticas que las representaban iban incluyendo las reivindicaciones específicas de la parcela de los trabajadores urbanos que habitaban las favelas. Concretamente, tanto el PTB como el PG poseían ya cierta inserción entre los favelados, aun cuando en el caso de este segundo partido su impuesta ilegalidad le restaba posibilidades de ganar adeptos entre una población amenazada permanentemente por la arbitrariedad de los organismos represivos.

Los diputados electos de ambas fuerzas políticas, una vez que consiguieron garantizar sus mandatos amenazados por una maniobra política del lacer-

42 Entre otros, véase Licia Valladares "Associacooes voluntarias na favela", en Ciência e Cultura, 29 (12), São Paulo, diciembre de 1977.

43 Véase entre otros: Luis A. Machado da Silva, "A política na favela", en Citdernos Brasileiros, año 14, núm. 41, Río de Janeiro, mayo-junio de 1967; Carlos A. Medina, A favela e o demagogo, Livraria Martins Editóra, São Pailo, 1954. y Anthony y Elizabeth Leeds, op. cit. Por otra parte estas afirmaciones debieran ser relativizadas por el hecho de que el sistema político hasileño excluía como votante a la pobla. ción analtabeta. 
dismo, ${ }^{4}$ propiciaron debates en el interior de las favelas a fin de elaborar propuestas a ser presentadas en la Asamblea Constituyente, para ser introducidas en la nueva Constitución de la Guanabara. Su proyecto en relación a las favelas era que el Estado expropiara los terrenos sujetos a desalojo inminente; otorgar facilidades a los favelados para que construyesen y mejorasen sus barracos; garantizar un mínimo de $3 \%$ del presupuesto estatal para destinarlo a obras de mejoramiento (agua, luz, drenaje, escuelas). ${ }^{45}$ Como vimos, aunque se consiguió introducir el punto relativo a destinar un porcentaje del presupuesto para el problema de las favelas, el poder real del ejecutivo le permitió que utilizara los recursos de acuerdo a su propio programa. Se actualizaba así la propuesta que alternativa e históricamente sostendrán el gobierno y los favelados: erradicación versus urbanización. Los representantes de las fuerzas políticas populares, reivindicando las mejoras en los núcleos originales y solicitando que el Estado impidiese el desalojo, estaban presentando una propuesta de carácter inmediato. Pero, al mismo tiempo, introducían en su estrategia global alternativa la reforma urbana y la agraria como el camino a seguir para solucionar efectivamente los problemas habitacionales del pueblo.

El diputado Hércules Correia, presentando su trabajo a la Asamblea, relató las actividades que fueron desarrolladas en la subcomisión competente por los miembros de la minoría que forman parte de la misma. Señaló como una de las victorias obtenidas la inclusión en el proyecto de la Constitución del artículo que determina la dotación del tres por ciento de la recaudación del Estado para la urbanización de favelas, de autoría de los representantes del PIB y del PSB... llamó al pueblo a luchar decididamente para hacer aprobar una Constitución democrática y progresista, señaló el ejemplo del pueblo cubano: Cuba, dijo, dio el ejemplo a todos los pueblos de América Latina. La Revolución hace la reforma urbana que da vivienda a todo el pueblo... La defensa de la Revolución Cubana es parte de la lucha de cada pueblo de América Latina. ${ }^{46}$

Otras fuerzas políticas que comenzaban a desarrollarse en el campo popular, particularmente las que poseían una base estudiantil y católica como es el caso de Acción Popular, confluyeron también a las favelas en busca de adeptos.

En realidad, cuando el gobierno comenzó a efectivizar su programa de erradicación no existía aún una propuesta alternativa capaz de crear cierto

44 La Ley Federal que creó el Estado de la Guanabara, al trasladarse la capital de la República a Brasilia, decía que los "vereadores" (concejales) del Antiguo Distrito Federal se transformarían en diputados de la Asamblea Legislativa luego de promulgarse la nueva Constitución estatal. Sin embargo, para efectivizar esto fue necesario generar una movilización popular, puesto que la mayoría de la Constituyente y el Poder Ejecutivo estatal intentaron desconocer la vigencia de los mandatos.

45 Véase Novos Rumos, Río de Janeiro, 27 de enero al 2 de febrero de 1961.

46 Novos Rumos, Río de Janeiro, 10 al 16 de febrero de 1961. 
espacio de negociación. Las movilizaciones que organizaron los favelados a la Cámara Legislativa a fin de solicitar apoyo frente a los primeros desalojos, no alcanzaban para exigir al gobierno un cambio de actitud. La carencia de una estructura organizativa anterior, en la cual tuviese cabida el conjunto de las reivindicaciones de los pobladores de las favelas y en la cual se expresaran los proyectos políticos populares existentes, impidió que la cuestión de las favelas adquiriese cierto grado de centralidad, en medio de una escena política en la cual la inestabilidad y la amenaza de golpe estaban ya presentes.

La agrupación sectorial que se activó en esos momentos, la Federación de Asociaciones de Favelas del Estado de la Guanabara, intentaba ganar representatividad en este sector urbano en un momento en que la correlación de fuerzas comenzaba a alterarse en contra del campo popular. La desarticulación de la misma, una vez producido el golpe militar del 64, a través de una eficaz represión policial a sus dirigentes, fue el camino que la Federación debió compartir con el conjunto de las organizaciones populares.

\section{Consideraciones finales}

El recorte en el tiempo por el que he optado en este trabajo a fin de analizar la relación existente entre las instituciones de Estado y las organizaciones sociales de villeros y favelados, ha respondido al interés de contribuir al conocimiento de uno de los períodos menos abordados por la investigación social. Los pueblos de América Latina luchan por formas políticas democráticas. La reconstrucción de la historia de un segmento de las clases populares en el momento en que existían expectativas de profundizar las democracias restrictivas de entonces, puede constituir una contribución en el necesario proceso de acumulación de experiencias protagonizadas por las mismas.

Las dos realidades que he analizado presentan un conjunto de especificidades y puntos en común que merecen ser anotados en el final de este trabajo. Lo primero que debe mencionarse es que tanto las favelas como las villas miseria, son barrios populares constituidos a partir de la invasión familiar o individual de tierras de propiedad pública. Aun cuando posteriormente se desarrolle en su interior un submercado de barracos, estos barrios se diferencian de los denominados fraccionamientos clandestinos, que proliferan décadas después en dichos contextos, porque el acceso a la tierra se produjo a través de una serie de mecanismos sociales más que comerciales.

Este rasgo, que algunos autores tienden a descalificar al preocuparse 
par las posibilidades de organización social que pueden desarrollar estos trabajadores urbanos, es de fundamental importancia en los dos casos estudiados. Para esta parcela de trabajadores urbanos, es el territorio común que habitan lo que incrementa la posibilidad de participar en organizaciones sociales que les permitan mejorar sus condiciones de vida o que los representen cuando su propia existencia en el medio urbano se ve amenazada por el desalojo. En los dos países considerados no existen formas generalizadas de tenencia confusa de la tierra, sino que la propiedad privada es el elemento organizador del uso y ocupación del suelo. El habitar tierras de manera ilegal coloca a esta población desde el inicio en una situación diferencial lo que, ciertamente, ha servido de fundamento para la elaboración de preconceptos socialmente aceptados sobre la misma, mediante los cuales se han justificado los más variados tipos de procesos de desalojo.

Pero ello no implica desconocer que la identidad de villeros y favelados se construye principalmente a partir de los elementos comunes al territorio que habitan y entre los cuales la ilegalidad es el de mayor fuerza.

Por otra parte, la coyuntura analizada se caracteriza por la presencia de los organismos internacionales que debutan en el ofrecimiento de orientaciones y recursos para la elaboración de las políticas urbanas. En las situaciones de escasez de recursos que vivían ambas economías nacionales para hacer frente a la magnitud de las necesidades sociales que existían y en medio de la disputa que podía entablar en relación a los mismos el capital a fin de que el Estado asegure las condiciones generales de su realización, las agencias internacionales encontraban un campo propicio para su actuación. Así, la cuestión de la vivienda popular fue introducida definitivamente en las agendas gubernamentales de los más diferentes niveles de gobierno con condicionamientos externos. En los dos casos que analizamos, aun cuando no se ha profundizado la cuestión de los objetivos últimos que persigue la acción de los organismos internacionales, se puede advertir de qué manera los mismos se relacionaron con los gobiernos locales (comunal en uno y estatal en el otro) elaborando y poniendo en marcha una política de vivienda popular que no se correspondía con la posición y las acciones emprendidas por los gobiernos nacionales. Los programas de vivienda popular, que consistían fundamentalmente en la erradicación y la constitución de nuevos barrios en la periferia lejana y que se efectivizan posteriormente, durante los regímenes militares que se imponen en ambos países, fueron ideados por técnicos nacionales y extranjeros sin que existiese ningún grado ni tipo de consulta a los propios afectados, a comunidades de profesionales, a fuerzas políticas que ya habían intentado elaborar proposiciones en torno a la cuestión.

En cierta medida puede decirse que la "erradicación masiva" poseía inclusive un alto grado de improvisación y las posibilidades de efectivizarla no sólo encontraron obstáculos entre los pobladores sino en la propia capacidad de las instituciones encargadas de implementar estos programas. Desde la perspectiva de los pobladores, el alto costo de la erradicación ya 
había sido comprobado por los villeros a través de los programas que anteriormente se habían intentado desarrollar; esto permitió profundizar la naciente organización de los mismos puesto que habían sabido idear formas definidas de acción. En el caso de las favelas, en cambio, el impulso a la organización llegaba tarde pues el cambio de la coyuntura política tornaba imposible lograr ese objetivo ante condiciones generales tan adversas. No se trataba ya de oponerse a medidas puntuales sino a un estructurado plan que el régimen militar permitirá efectivizar. 